\title{
Integrated economic and environmental analysis of agricultural straw reuse in edible fungi industry
}

\author{
Wencong Lu ${ }^{1}$, Shuao $\mathrm{Yu}^{1}{ }^{\text {, Yongxi Ma }}{ }^{\text {Corresp.. }}{ }^{2}$, Hairong Huang ${ }^{2}$ \\ ${ }^{1}$ China Academy for Rural Development, Zhejiang University, Hangzhou, Zhejiang, China \\ 2 School of Economics and Management, Zhejiang Sci-Tech University, Hangzhou, Zhejiang, China \\ Corresponding Author: Yongxi Ma \\ Email address: myx@zstu.edu.cn
}

Background: China currently faces severe environmental pollution caused by burning agricultural straw; thus, resource utilization of these straws has become an urgent policy and practical objective for the Chinese government. Methods: This study develops a bioeconomic model, namely, "straw resource utilization for fungi in China (SRUFIC)," on the basis of a field survey of an edible fungi plant in Zhejiang, China, to investigate an integrated economic and environmental performance of straw reuse in fungi production. Five scenarios, which cover changes in the production scale, wage level, and price fluctuations of the main product and inputs, are simulated. Results: Results reveal that 1 ) the pilot plant potentially provides enhanced economic benefits and disposes added agricultural residues by adjusting its production strategy; 2 ) the economic performance is most sensitive to fungi price fluctuations, whereas the environmental performance is more sensitive to production scale and price of fungi than other factors; 3 ) expanding the production scale can be the most efficient means of improving the performance of a plant economically and environmentally. Discussion: Overall, agricultural straw reuse in the edible fungi industry can not only reduce the environmental risk derived from burning abandoned straws but also introduce economic benefits. Thus, the straw reuse in the fungi industry should be practiced in China, and specific economic incentive policies, such as price support or subsidies, must be implemented to promote the utilization of agricultural straws in the fungi industry. 


\section{Integrated economic and environmental analysis of 2 agricultural straw reuse in edible fungi industry}

3 Wencong $\mathrm{Lu}^{1}$, Shuao $\mathrm{Yu}^{1}$, Yongxi $\mathrm{Ma}^{2^{*}}$ and Hairong Huang ${ }^{2}$

4

51 China Academy for Rural Development, Zhejiang University, Hangzhou, China;

62 School of Economics and Management, Zhejiang Sci-Tech University, Hangzhou, China;

7

8 - Corresponding author: Prof. Dr. Yonxi Ma, myx@zstu. edu. cn 9 


\section{Abstract:}

12 Background: China currently faces severe environmental pollution caused by burning 13 agricultural straw; thus, resource utilization of these straws has become an urgent policy and 14 practical objective for the Chinese government.

15 Methods: This study develops a bio-economic model, namely, "straw resource utilization for 16 fungi in China (SRUFIC)," on the basis of a field survey of an edible fungi plant in Zhejiang, 17 China, to investigate an integrated economic and environmental performance of straw reuse in 18 fungi production. Five scenarios, which cover changes in the production scale, wage level, and 19 price fluctuations of the main product and inputs, are simulated.

20 Results: Results reveal that 1) the pilot plant potentially provides enhanced economic benefits 21 and disposes added agricultural residues by adjusting its production strategy; 2) the economic performance is most sensitive to fungi price fluctuations, whereas the environmental 23 performance is more sensitive to production scale and price of fungi than other factors; 3 ) 24 expanding the production scale can be the most efficient means of improving the performance 25 of a plant economically and environmentally.

26 Discussion: Overall, agricultural straw reuse in the edible fungi industry can not only reduce the environmental risk derived from burning abandoned straws but also introduce economic benefits. Thus, the straw reuse in the fungi industry should be practiced in China, and specific economic incentive policies, such as price support or subsidies, must be implemented to promote the utilization of agricultural straws in the fungi industry. 


\section{Introduction}

China is one of the major agricultural nations in the world, this country produces 900 million tons of agricultural straw annually, $20 \%$ of global straw output. In rural China, agricultural straws have been used traditionally as an important energy source for cooking and heating. However, farmers currently have access to additional convenient substitute household energy sources, such as electricity and gas. The residue straw is difficult to be disposed on the field. In 2015 More than 180 million tons of straw were burned or abandoned (MOA, 2016). However, burning straw releases inhalable particulate matter (PM10 and PM2.5), greenhouse gases $\left(\mathrm{CH}_{4}\right.$ and $\left.\mathrm{CO}_{2}\right)$, nitrogen oxides ( $\left.\mathrm{NOx}\right)$, and sulfur dioxide $\left(\mathrm{SO}_{2}\right)$, which brought heavy air pollution problems and severely affected ecological systems and human health in China (Shi et al., 2014). Moreover, agricultural straws can be used as biofuel, fodder, and fertilizer. Therefore, burning straws not only damages the environment but also wastes valuable resources.

The huge amount of wasted resources and the severe pollution of the environment caused by burning agricultural straw warn the Chinese government of the urgent requirement for developing new strategies for disposing of and reusing agricultural straws. In 1999, the Ministry of Environmental Protection (MEP) of China has announced the "Regulations on straw burning prohibition and comprehensive utilization", prohibits straw burning in certain areas and proposes a target ratio (60\%) of comprehensive utilization (MEP, 1999). Then, the "Renewable Energy Law" and the Circular Economy Promotion Law", encourage the comprehensive utilization of agricultural straws (NPC, 2005, 2008). The National Development and Reform Commission (NDRC) of China formulated a "Medium and Long-term Development Plan for Renewable Energy in China" (NDRC, 2007), and then China's State Council (CSC) issued the "Notice on Promoting Comprehensive Utilization of Crop Straws" to clearly demonstrate the straw program for each authority level (CSC, 2008). The number of straw burning sites has effectively decreased given the implementation of these policies; however, the immense challenge of utilizing massive amounts of straws still. Then, the "Circular Economy Development Strategy" (CSC, 2013), "Technology Catalog of Crop Straw Comprehensive Utilization” (NDRC and MOA, 2014), and "Instruction on Further Promoting Comprehensive Utilization of Crop Straw" (CSC, 2015) were introduced to update and supplement the abovementioned policies; these policies also highlighted five major categories of utilization, that is, fertilizers for crops, feeds for livestock, feed-stocks for industry, media for fungi, and biomasses for energy. Furthermore, 
63 these policies have indicated that agricultural straws in China shall be "reused as recycled 64 resources (RRR)," which can not only reduce negative environmental impacts but also increase economic benefits. The resource utilization of agricultural straws has become a significant policy

66 and practical objective for the Chinese government (MOA, 2017).

Many previous studies have discussed the techniques involved in the five categories of straw utilization; numerous studies focus on energy utilization in terms of environmental or economic effects. Research in developed and developing countries have verified that applying strawderived electricity, gas, and bioethanol can reduce the global warming potential to the world and generate much less human- or eco-toxicities than traditional fossil energies, such as coal-fired electricity and natural gas (Nguyen et al., 2013a; Nguyen et al., 2013b; Soam et al., 2016; Song et al., 2016; Van Nguyen et al., 2016; Weiser et al., 2014). Moreover, the energy utilization of agricultural straws is economically viable and efficient in East Europe (Cosic et al., 2011; Dodic et al., 2012; Zbytek et al., 2016) and Asia (Delivand et al., 2012; Singh, 2016; Sun et al., 2017), especially in terms of the price of biomass products and costs incurred in collection, processing, and facilities. For the utilization of fertilizer, several long-term field experiments have confirmed that straw compost returning can improve the nutrient cycling structure of farming land using an intensive cropping system and reduce the risk of excessively fertilized soils (Kim et al., 2017; Roca-Perez et al., 2009; Tian et al., 2016; Zheng et al., 2015). Another branch of studies investigates greenhouse gas (GHG) emissions from straw returning, calculates global warming potentials (GWP) of different returning modes (Hu et al., 2016; Wu et al., 2015; Zhang et al., 2015). Monteleone et al. (2015) examine an optimal trade-off between "straw to soil" and "straw to energy", the results show that the use of straw for energy generation consistent with optimizing the cropping system are key factors for long-term environmental sustainability in terms of the GHG reduction and fossil displacement. However, very limited studies have accomplished an environmental or economic analysis related to the other three categories of straw utilization. Feeding animals with pretreated straws (e.g., silage and ammonification) can possibly reduce the GHG emission from livestock (Fan et al., 2006). Xi and Zhou (2015) introduce a circular economy of agricultural straw utilization as substrates for edible fungi, but no quantitative analysis of environmental or economic effects has been conducted.

Most studies have adopted a life cycle approach to assess the environmental and economic performances of straw utilization (Clare et al., 2015; Delivand et al., 2012; Hong et al., 2016; 
94 Kunimitsu and Ueda, 2013; Nguyen et al., 2013a; Nguyen et al., 2013b; Song et al., 2017). This

95 approach can clearly indicate the input and output at each phase of the life cycle of the objective 96 product or process of utilization. However, the life cycle approach is essentially a descriptive 97 method that relies on life cycle inventory data and does not reveal the dynamic, interactive 98 relationship between economic behavior and environmental systems. A possible alternative 99 method is applying bio-economic (or environmental-, ecological-economic) models, which have 100 been widely accepted by agricultural or ecological economists when analyzing the integrated 101 effects of environmental and economic systems (Arfini, 2012). A bio-economic model, which 102 merges biophysics and economics, can investigate the multi-disciplinary and multi-scale effects 103 of a given problem through biophysical equations and economic programming methods 104 (Filchman et al., 2011).

105 This paper develops a specific model based on a bio-economic framework to combine the 106 environmental and economic aspects into an integrated analysis of agricultural straw utilization 107 in the study of a fungi enterprise from Zhejiang, China. This study aims to optimize the quantity 108 of disposed agricultural straws (environmental effect) and maximize the economic returns 109 (economic effect) simultaneously under subjective constraints. The economic and environmental 110 effects are assessed by bio-economic model simulations under different scenarios. Sensitivity 111 analysis is also incorporated into the model simulations to derive the potential impact from 112 changes in the production scale and price of input materials and products.

113 The rest of this paper is organized as follows: Section 2 introduces a profile of the 114 participating fungi enterprise and the process of fungi production; Section 3 describes the bio115 economic model for integrated environmental and economic analysis for agricultural straw 116 utilization in the fungi industry, along with twelve scenarios of model simulation; Section 4 117 presents the simulation results of the environmental and economic effects in different scenarios 118 and discusses several critical points with respect to practical recommendations. Section 5 119 summarizes the results of the study and highlights several policy implications.

\section{Study case}

121 This study was conducted in a pilot edible fungi plant in Jinhua City, Zhejiang Province, 122 China. The pilot plant was established in 2004, and currently, the pilot plant has 5,000 $\mathrm{m}^{2}$ of

123 fungi growing room with two lines of production. The pilot plant has disposed of 1,080 tons of 
124 straw and 2,520 tons of other residues (including cottonseed hulls, bagasse, bran and cornstarch)

125 in 2015. A total of 6 million bags of fungi and 3,600 tons of edible fungi are produced, thereby 126 generating a considerable economic return of CHY1 22.2 million, along with CHY 43.4 million

127 total benefit and CHY 21.2 million total cost. The pilot plant also provides 85 fixed work 128 positions and dozens of flexible part-time jobs to the local community. The residue straw 270 ton 129 was burn in the field that brought heavy air pollution.

130 In the past decade, the pilot plant has developed an integrated, environmentally friendly 131 processing system to produce fungi (Fig. 1). All masses of fungi growth medium are agricultural 132 or forestry wastes; $80 \%$ of which are crop straws and cottonseed hulls; the remaining $20 \%$ 133 consists of bagasse, bran and cornstarch. The first step of growing fungi is preparing nutrient 134 growth medium by proportionately mixing the compost of crop straw, cottonseed hulls, and 135 bagasse proportionately. The composting procedure in the medium preparation phase lasts 6 136 months. The fertile fungi medium is packed into fungi bags. Each fungi bag must be autoclaved 137 and sterilized in a furnace for at least $4 \mathrm{~h}$. Then, the fungi spawns are placed into the cavities for 138 mycelium incubation. This phase lasts for approximately 100-120 days. Finally, the fungi are 139 harvested.

140 The used medium and remaining fungi residue are generally utilized in four ways. The 141 residues are 1) collected as fertile materials for secondary fungi bags $(20 \%-30 \%), 2)$ delivered to 142 livestock or poultry farms as organic feeds $(30 \%-40 \%), 3)$ mixed with the sewage generated 143 during fungi growing as fertilizers (20\%-30\%), and 4) dried out into biofuels (10\%-20\%).

Figure 1. Edible fungi production system of the pilot plant.

\section{Integrated economic and environmental analysis}

\subsection{Modelling}

147 Bio-economic models are widely used on an individual or multiple agricultural production 148 systems of the crop, livestock, and fisheries because these models can be applied across borders 149 of disciplines between biophysical equations and economic behaviors (Arfini, 2012; Janssen and 150 van Ittersum, 2007; Kragt et al., 2016). Linear programming (LP) method is commonly selected

${ }^{1}$ CHY: Chinese Yuan, China's currency unit. 
151 as the mathematical approach to solving optimization problems in bio-economic models for the

152 following reasons: this method enables multi-restrictions to be considered simultaneously, offers

153 a specific and valid goal-seeking procedure, and outputs model results easily when variables are

154 changing (Lu et al., 2014; Ma et al., 2014). For this study, the "straw resource utilization for

155 fungi in China (SRUFIC)" model based on the general structure of the "ecological-economic"

156 model (Wossink et al., 2001; Pacini 2003; Pacini et al., 2004) is constructed to analyze the

157 integrated environmental and economic effects in the pilot enterprise.

$$
\pi(\mathrm{X}, \mathrm{Y}, \mathrm{Z}, \mathrm{B} ; \Theta)=\operatorname{MAX}\{[\operatorname{Pr} \times Y-W \times X]-C\}
$$

160

161

162

163

164

165

166

167

168

169

170

171

172

173

174

175

176

177

178

179

180

$$
\text { S. T. : T }(X)=\{Y \mid(Y, X ; \Theta) \in T\}
$$$$
B \leq \bar{B}
$$$$
\mathrm{G}(Z, Y, X ; \Theta) \geq G_{0}
$$
major pollution elements for soil and water.

Equation [1] expresses the profit maximization function of the SRUFIC model in terms of vectors of material input $(\mathrm{X})$, product output $(\mathrm{Y})$, environmental indicator $(\mathrm{Z})$, resource budget (B), technological level $(\Theta)$, fixed cost $(\mathrm{C})$, price of products $(\mathrm{Pr})$, and price of inputs $(\mathrm{W})$. The fixed cost, technological level, and prices are considered constants in one stage of the programming. Equations [2]-[4] are model subject constraints to the programming. The fungi production function, $\mathrm{T}(\mathrm{X})$, is defined as a transformation process that combines materials and a group of products under a certain technological level. $G(Z, Y, X ; \theta)$ refers to the ultimate environmental effects of the fungi production system with respect to the given indicators of input, output, environment, and technology. Thus, the "zero emission" target can be realized in the production system because all production residues, including sewage, can be utilized in several ways. The ultimate environmental effect is described as the "treatment effect on agricultural residues (straws) in fungi production," or the quantity disposed of by the plant in general. G0 is the benchmark of this effect. Material balance approach (MBA) is used to build a biophysical formulation that traces the environmental effects of the fungi production system. The MBA means that materials in a physical system are not lost, and that material inputs in processes end up in either stock accumulation or material output flows (Nijkamp et al., 1997). All input nutrients result in final products or wastes (Ma et al., 2014). The most important nutrients, that is, nitrogen $(\mathrm{N})$ and phosphorus $(\mathrm{P})$, are considered in the MBA because excess $\mathrm{N}$ and $\mathrm{P}$ are also 
181

182

183

184

185

186

187

188

189

190

191

192

193

194

195

196

198

199

200

201

202

203

204

205

206

207

$$
R=\sum_{i}^{n} x_{i}(N, P, K)-\sum_{j}^{m} y_{j}(N, P, K),
$$

where $\mathrm{R}$ represents the portion released into the surroundings. $\mathrm{R}$ can be considered less than or equal to zero because all the residues and wastes are utilized as by-products in this study.

In the SRUFIC model, $B \leq \bar{B}$ denotes that finite producing resources are available in the production system. Credit and land are important factors which increases the production and income of the farmers (Hussain, 2012). In rural areas of China, the small farms face many difficulties to get enough loan credit and land to expand their production capacity. The main resource constraints considered in this study include liquid capital and production capacity.

Liquid capital constraint. The fungi enterprise should have a full payment capability for expenditures on the materials of a medium, spawns, salary of workers, electricity, and freshwater to sustain the production system.

$$
\sum_{i}^{n} e_{i} \leq \bar{E}
$$

Where $e_{i}=w_{i} \times x_{i} ; e_{i}, w_{i}$ and $x_{i}$ are the expenditure, price, and quantity of input I, respectively; $\mathrm{n}$ is the number of inputs; and $\bar{E}$ is the maximum amount of viable liquid capital.

Production capacity constraint. Facilities in the enterprise undergo regular maintenance; thus, no additional production line can be equipped.

$$
\sum_{j}^{m} y_{j} \leq \bar{Y}
$$

where $y_{j}$ refers to the output of product $\mathrm{j}, \mathrm{m}$ is the number of products (including byproducts), and $\bar{Y}$ is the current maximum production capacity.

\subsection{Data source}

The primary data were obtained through a field survey of the pilot plant in 2016. The frontline workers, technical staff, department managers, and enterprise owners participated in the survey. A detailed production dataset that covers economic and environmental performances has been established based on several annual and seasonal reports from 2015. The inputs (including crop straw, cottonseed hulls, and bagasse), products, and by-products were calculated by dividing the value by quantity. The nutrient content data and technical parameters used in this study were offered by the technical staff from the plant. 


\subsection{Simulation scenarios}

Five simulation scenarios are constructed in this study to evaluate the environmental and economic effects of straw utilization in the fungi production under different market situations. Each scenario covers the two-way fluctuation of the study variables.

Scenario I: Fungi price. The fungi price is assumed to fluctuate in this scenario. Fungi price is highly related to the total economic income of this pilot plant and reflects market demand and supply information, which can impact the production decisions of enterprise owners.

Scenario II: Agricultural straw and Scenario III: Cottonseed hull. The two scenarios consider the price fluctuation of the two main material inputs, namely, agricultural straw and cottonseed hull. These inputs represent $80 \%$ of the weight of the fungi growth medium. The prices of straw and hull comprise the largest portion of the total production cost. The quantities of straw and hull that the fungi plant disposes of are also determined by these prices.

Scenario IV: Wage. This scenario considers the changes in labor price. A High (or low) wage level may affect the employment decisions of enterprise owners and increase (or decrease) the expenditure on salaries.

Scenario V: Scale. In this scenario, the production capacity constraint in the SRUFIC model is loosened. The pilot plant is allowed to add new production facilities to extend the input scale or reduce workload to reduce the input scale. The potentially technical parameters are assumed to be unchanged in this scenario (Smith et al. 2016).

\section{Results and discussion}

\subsection{Simulation results}

\subsubsection{Output and Input}

A general algebraic modeling system (GAMS) is used to solve the programming results of the SRUFIC model. Model calibration and validation were conducted previously to check the consistency between real situations and model scenario solutions. The scenarios studied are possible future market conditions and possible production scales "Status quo" represents the actual situation according to the pilot plant survey. "Base" scenario refers to the optimized results calculated by a model mathematical programming, which represents the optimal production situations under present constraints. Moreover, Optimization results are considered 
237 the baseline for succeeding simulation scenarios (Smith, et al. 2016). The prices and quantities of

238 output and input which described the production function in the plant are reported in Table 1.

239

240

241

242

243

244

Table 1. The baseline data in the case study

Optimization can increase the harvest by 282 tons of fungi and 115 tons of by-products more than "Status quo" after adding 98 tons of medium and 10 tons of spawn. This result reveals that the pilot plant is capable of expanding its production intensity under the current set of constraints. Meanwhile, there is a better environmental effect by no straw burning.

Table 2 presents the results of fungi production output and input under different simulation scenarios.

Table 2. Simulation results of output and input quantities.

For the fungi price scenario, a high market price urges the plant to improve its production intensity. If the price of fungi increases by $7 \%$, then the pilot plant will hire six more workers than base scenario. On the contrary, the input and output will decline if the price of fungi decreases.

In Scenarios II and III, the input price decrease allowed the plant to purchase additional production materials. The growth extents, especially in Scenario III, although both rows of "price decrease 10\%" in agricultural straw and cottonseed hull have shown rises in each column. The straws are evidently smaller than in previous scenarios. One possible explanation might be due to agricultural straws and cottonseed hulls are generally less expensive, and their prices are not as elastic. Thus, plant owners are less sensitive to straws and hulls than to the other elements of production decisions. In Scenario IV, low wage levels will stimulate the pilot plant to use additional workers as presumed, thereby leading to an upward trend of initial inputs and final outputs. From the perspective of production, the changes in output and input caused by the decline and upraise in wages are relatively close; both of which are smaller than in Scenario III.

In Scenario V, a scale shrink of $10 \%$ results in the decrease in every column, and the reverse occurs in terms of scale expansion. The impact is more obvious in scale shrink than in scale expansion. For example, fungi production increases by 276 tons (less than 10\%) in "expand 10\%," but decreases by 480 tons (more than 10\%) in "shrink 10\%." These results reveal that the production behaviors of the pilot plant are more sensitive to scale shrink than to scale expansion; moreover, the pilot plant is in the phase of decreasing returns to scale. 
267

268

269

270

271

272

273

274

275

276

277

278

279

280

281

282

283

284

285

286

287

288

289

290

291

292

293

294

295

296

\subsubsection{Economic and Environmental performances}

Table 2 presents the results of the economic and environmental performances in the pilot fungi plant under different simulation scenarios. In this paper, economic performance refers to the total benefit, cost, and net benefit derived from the fungi plant. Environmental performances refer to the quantities of agricultural straw and other agricultural residues disposed of, such as cottonseed hull and bagasse. Optimization enables the plant to generate more total benefit growth (CHY 3.3 million) than total cost growth (CHY 0.1 million) than Status quo, thereby generating an increase of CHY 3.2 million net benefit. Furthermore, instead of burning 270 tons of straws in status quo, the plant under Optimization, which assumes "zero straw burning", will dispose additional 66 tons of straw, and the rest 204 tons are preferred returning back to field. The pilot plant shall adjust its production strategy to obtain additional profit and simultaneously dispose of additional agricultural straw for the local community. Similar to Table 1, the Optimization results in Table 3 are then considered a reference for succeeding simulation scenarios.

Table 3. Simulation results of economic and environmental performances.

Scenarios I-IV are essentially price scenarios, with Scenario I relating to output price and the other three relating to input price. The plant is motivated to increase input and expand its output to generate high income when the output price increases. In Scenario I, a 10\% fungi price increase exhibited significant positive effects on the economic and environmental performances. The net income grows by $28 \%$ to CHY 3.6 million, and the sum amount of disposition increases by 237 tons, including 81 tons of agricultural straws. However, if input prices increase, then the plant shall have less payment capability to hire as many workers as before or purchase the same amount of materials. Among the three input price scenarios, wage changes can cause the most significant fluctuations in each economic or environmental column. Straw price changes exhibit the least impact on both performances, and the cottonseed hull scenario lies in the middle.

A large production scale can induce increases in the total benefit, cost, and net benefit and dispose of additional 82, 128, and 29 tons of agricultural straw, cottonseed hull, and bagasse residue, respectively. The economic performance is similar to the output and input results discussed previously because economic items are equal to quantities multiplied by constant prices. This result may reveal that the fungi production behavior of the pilot plant under the existing conditions fits the law of diminishing marginal returns. 
297

298

299

300

301

302

303

304

305

306

307

308

309

310

311

312

313

314

315

316

317

318

319

320

321

322

323

324

325

\subsection{Sensitivity analysis}

Comparisons between Status quo and Optimization reveal that the pilot fungi plant can obtain more output under its current budget and other constraints. The plant shall adjust its producing strategy by generating extra medium and inputting additional spawn in the production system to improve economic benefit and dispose of large quantities of agricultural residues for the local community. For the rest of the scenarios, sensitivity results in Table 4 provide a clear picture of the economic and environmental performances of the pilot plant. The sensitivity results are exactly the same among the inputs because the medium proportion ratios of straw, hull, and bagasse are assumed to be constant. "Ag. Straw" is listed to represent environmental performances.

Table 4. Sensitivity results of economic and environmental performances.

In terms of economic performance, the total benefit and net benefit is most sensitive to fungi price fluctuations, followed by production scale and wage changes. Product price is key factor for the better economic performance. But for the cost and employment, the scale has the largest impact, followed with fungi price, wage and the other agricultural residues prices. For the environmental performance, the disposal of agricultural straws is more varied in scale and fungi scenarios than in other columns. The agriculture price has a minimal effect on the economic and environmental performance. These results may reveal that expanding the production scale can be an efficient means of achieving high economic returns and dispose of additional agricultural straws because market prices and average wage levels cannot be controlled by a single plant.

\section{Conclusions and policy implications}

The reuse of agricultural straws in the fungi industry is crucial in terms of reducing environmental pollution and promoting efficient resource utilization in agricultural production. A holistic, integrated bio-economic model is used in this study to achieve a comprehensive economic and environmental analysis. The fungi production and agricultural straw disposal systems are incorporated. The case study indicates that the resource utilization of agricultural straws in the edible fungi industry is feasible for economy and environment. The reuse of agricultural straws in the fungi industry can minimize the environmental risks of burned or abandoned straw and avoid "secondary pollution" in the process of straw treatment. 
This paper presents the following conclusion on the basis of the simulation analysis in the case study: The current use of straw resources is inefficient in the pilot fungi plant. The economic and environmental performances can be improved by increasing the medium and spawn inputs under the current production conditions. A large production scale increases income and improves environmental performance. However, the production behaviors of the pilot plant are more sensitive to scale shrinking than to scale expansion. An increase in the output price will stimulate the plant production and dispose of added agriculture straws. However, the economic and environmental performances of fungi production will deteriorate if the input prices increase. The sensitivity analysis also indicates that the economic performance is most sensitive to fungi price fluctuations and that the environmental performance is more sensitive to production scale and price of fungi than other factors.

From the perspective of policy instruments, devoting extra efforts to the comprehensive resource utilization of agricultural straws is necessary for Chinese farms to solve the problems of environmental pollution caused by leftover straws. Technological and environmental economic means should be applied comprehensively to "convert wastes into resources," promote economic and environmental benefits, and achieve sustainable development for agriculture. The reuse of agricultural straws in the fungi industry should be demonstrated and extended to suitable areas in China. The expansion of the production scale in the fungi plants should be encouraged to

344 enhance economic profits and improve environmental performances. Moreover, specific economic incentive policies, such as price support and subsidies, must be implemented to promote the resource utilization of agricultural straws in the fungi industry.

\section{7}

348

350

351

352

353

354

355

356

357

\section{References}

Arfini F. 2012. Bio-Economic Models Applied to Agricultural Systems. European Review of Agricultural Economics 39:884-888.

Clare A, Shackley S, Joseph S, Hammond J, Pan GX, and Bloom A. 2015. Competing uses for China's straw: the economic and carbon abatement potential of biochar. Global Change Biology Bioenergy 7:1272-1282.

Cosic B, Stanic Z, and Duic N. 2011. Geographic distribution of economic potential of agricultural and forest biomass residual for energy use: Case study Croatia. Energy 36:2017-2028.

CSC. 2008. Instruction on promoting comprehensive utilization of crop straw.

CSC. 2013. Development strategy for Circular economy and recent plan actions. 
358 CSC. 2015. Instruction on further promoting comprehensive utilization of crop straw buring prohibition.

360

361

362

363

364

365

366

367

368

369

370

371

372

373

374

375

376

377

378

379

380

381

382

383

384

385

386

387

388

389

390

391

392

393

394

395

396 Delivand MK, Barz M, Gheewala SH, and Sajjakulnukit B. 2012. Environmental and socioeconomic feasibility assessment of rice straw conversion to power and ethanol in Thailand. Journal of Cleaner Production 37:29-41.

Dodic SN, Zekic VN, Rodic VO, Tica NL, Dodic JM, and Popov SD. 2012. The economic effects of energetic exploitation of straw in Vojvodina. Renewable \& Sustainable Energy Reviews 16:397-403.

Fan X, Yang Z, and Li D. 2006. Feeds safety and hidden danger Chinese Journal of Animal Science 42:10-12.

Filchman G, Louhichi K, and Boisson JM. 2011. Modelling the Relationship Between Agriculture and the Environment Using Bio-Economic Models: Some Conceptual Issues.

Hussain, A. 2012. Impact of credit disbursement, area under cultivation, fertilizer consumption and water availability on rice production in pakistan (1988-2010). Mpra Paper, 808(2), 95-101.

Hong JL, Ren LJ, Hong JM, and Xu CQ. 2016. Environmental impact assessment of corn straw utilization in China. Journal of Cleaner Production 112:1700-1708.

Hu NJ, Wang BJ, Gu ZH, Tao BR, Zhang ZW, Hu SJ, Zhu LQ, and Meng YL. 2016. Effects of different straw returning modes on greenhouse gas emissions and crop yields in a ricewheat rotation system. Agriculture Ecosystems \& Environment 223:115-122.

Janssen S, and van Ittersum MK. 2007. Assessing farm innovations and responses to policies: A review of bio-economic farm models. Agricultural Systems 94:622-636.

Kim YJ, Choo BK, and Cho JY. 2017. Effect of gypsum and rice straw compost application on improvements of soil quality during desalination of reclaimed coastal tideland soils: Ten years of long-term experiments. Catena 156:131-138.

Kragt ME, Pannell DJ, McVittie A, Stott AW, Ahmadi BV, and Wilson P. 2016. Improving interdisciplinary collaboration in bio-economic modelling for agricultural systems. Agricultural Systems 143:217-224.

Kunimitsu Y, and Ueda T. 2013. Economic and environmental effects of rice-straw bioethanol production in Vietnam. Paddy and Water Environment 11:411-421.

Lu F, Wang XK, Han B, Ouyang ZY, Duan XN, and Zheng H. 2010. Net mitigation potential of straw return to Chinese cropland: estimation with a full greenhouse gas budget model. Ecological Applications 20:634-647.

Lu WC, Ma YX, and Bergmann H. 2014. Technological Options to Ameliorate Waste Treatment of Intensive Pig Production in China: An Analysis Based on Bio-Economic Model. Journal of Integrative Agriculture 13:443-454.

Ma YX, Lu WC, and Bergmann H. 2014. Economic and environmental effects of nutrient budgeting strategies in animal excreta treatment A case study from rural China. China Agricultural Economic Review 6:598-615. 
397 398

399

400

401

402

403

404

405

406

407

408

409

410

411

412

413

414

415

416

417

418

419

420

421

422

423

424

425

426

427

428

429

430

431

432

433

434

435

McCarl B, Meeraus A, and Van der Eijk P. 2012. McCarl Expanded GAMS user guide version 23.6. GAMS Development, Washington, DC.

MEP. 1999. Regulations on straw burning prohibition and comprehensive utilization. Available at http://www.zhb.gov.cn/gkml/zj/wj/200910/t20091022_171920.htm.

MOA. 2016. Main crops' straw resource utilization rate has reached $80 \%$. Available at http://www.moa.gov.cn/zwllm/zwdt/201605/t20160526 5151375.htm (accessed August 22 2017).

MOA. 2017. The 13th five-year plan for agricultral teconology develepment Available at http://www.moa.gov.cn/zwllm/ghjh/201702/t20170207 5469863.htm.

Monteleone M, Cammerino ARB, Garofalo P, and Delivand MK. 2015. Straw-to-soil or strawto-energy? An optimal trade off in a long term sustainability perspective. Applied Energy 154:891-899.

Nijkamp, P, Jeroen CJM. van den Bergh. 1997. New advances in economic modelling and evaluation of environmental issues. European Journal of Operational Research, 99(1), 180-196.

NDRC. 2007. Mid and long term development plan for renewable energy. Available at http://www.ndrc.gov.cn/zcfb/zcfbghwb/200709/t20070904 579685.html.

NDRC, and MOA. 2014. Technology catalog of crop straw comprehensive utilization.

Nguyen TLT, Hermansen JE, and Mogensen L. 2013a. Environmental performance of crop residues as an energy source for electricity production: The case of wheat straw in Denmark. Applied Energy 104:633-641.

Nguyen TLT, Hermansen JE, and Nielsen RG. 2013b. Environmental assessment of gasification technology for biomass conversion to energy in comparison with other alternatives: the case of wheat straw. Journal of Cleaner Production 53:138-148.

NPC. 2005. Law of Re-generable Energies for People's Republic of China. Available at http://www.zhb.gov.cn/gzfw_ 13107/zcfg/fl/201605/t20160522_343386.shtml.

NPC. 2008. Law of Circular Economy Promotion for People's Republic of China.

Pacini C, Wossink A, Giesen G, and Huirne R. 2004. Ecological-economic modelling to support multi-objective policy making: a farming systems approach implemented for Tuscany. Agriculture Ecosystems \& Environment 102:349-364.

Roca-Perez L, Martinez C, Marcilla P, and Boluda R. 2009. Composting rice straw with sewage sludge and compost effects on the soil-plant system. Chemosphere 75:781-787.

Sargent RG. 2005. Verification and validation of simulation models. Proceedings of the 37th conference on Winter simulation. Orlando, Florida: Winter Simulation Conference. $p$ 130-143.

Shi TT, Liu YQ, Zhang LB, Hao L, and Gao ZQ. 2014. Burning in agricultural landscapes: an emerging natural and human issue in China. Landscape Ecology 29:1785-1798.

Singh J. 2016. Identifying an economic power production system based on agricultural straw on regional basis in India. Renewable \& Sustainable Energy Reviews 60:1140-1155. 
436 Smith, EG, Card, G, \& Young, DL. 2006. Effects of market and regulatory changes on livestock

437

438

439

440

441

442

443

444

445

446

447

448

449

450

451

452

453

454

455

456

457

458

459

460

461

462

463

464

465

466

467

468

469

470

471

472

473

manure management in southern alberta. Canadian Journal of Agricultural Economics/revue Canadienne Dagroeconomie, 54(2), 199-213.

Soam S, Kapoor M, Kumar R, Borjesson P, Gupta RP, and Tuli DK. 2016. Global warming potential and energy analysis of second generation ethanol production from rice straw in India. Applied Energy 184:353-364.

Song GB, Song J, and Zhang SS. 2016. Modelling the policies of optimal straw use for maximum mitigation of climate change in China from a system perspective. Renewable \& Sustainable Energy Reviews 55:789-810.

Song SZ, Liu P, Xu J, Chong CH, Huang XZ, Ma LW, Li Z, and Ni WD. 2017. Life cycle assessment and economic evaluation of pellet fuel from corn straw in China: A case study in Jilin Province. Energy 130:373-381.

Sun YF, Cai WC, Chen B, Guo XY, Hu JJ, and Jiao YZ. 2017. Economic analysis of fuel collection, storage, and transportation in straw power generation in China. Energy 132:194-203.

Tian YQ, Wang Q, Zhang WH, and Gao LH. 2016. Reducing environmental risk of excessively fertilized soils and improving cucumber growth by Caragana microphylla-straw compost application in long-term continuous cropping systems. Science of the Total Environment 544:251-261.

Van Nguyen H, Nguyen CD, Van Tran T, Hau HD, Nguyen NT, and Gummert M. 2016. Energy efficiency, greenhouse gas emissions, and cost of rice straw collection in the mekong river delta of vietnam. Field Crops Research 198:16-22.

Weiser C, Zeller V, Reinicke F, Wagner B, Majer S, Vetter A, and Thraen D. 2014. Integrated assessment of sustainable cereal straw potential and different straw-based energy applications in Germany. Applied Energy 114:749-762.

Wu YP, Liu T, Peng Q, Shaaban M, and Hu RG. 2015. Effect of straw returning in winter fallow in Chinese rice fields on greenhouse gas emissions: evidence from an incubation study. Soil Research 53:298-305.

Xi Y, and Zhou X. 2015. Research on the system of resource utilization for agricultural wastes in China from the perspective of industry chain of circular economy. Journal of Jiangnan University (Humanities \& Social Science) 14:74-81.

Zbytek Z, Dach J, Pawlowski T, Smurzynska A, Czekala W, and Janczak D. 2016. Energy and economic potential of maize straw used for biofuels production. In: Demetrescu I, Oh K, Kaushik NK, Butu A, and Othman F, eds. 2016 3rd International Conference on Chemical and Biological Sciences.

Zhang ZS, Guo LJ, Liu TQ, Li CF, and Cao CG. 2015. Effects of tillage practices and straw returning methods on greenhouse gas emissions and net ecosystem economic budget in rice wheat cropping systems in central China. Atmospheric Environment 122:636-644. 
474 Zheng L, Wu WL, Wei YP, and Hu KL. 2015. Effects of straw return and regional factors on 475 spatio-temporal variability of soil organic matter in a high-yielding area of northern 476 China. Soil \& Tillage Research 145:78-86.

477 


\section{Figure 1}

Edible fungi production system of the pilot plant

The first step is preparing nutrient growth medium by proportionately mixing the compost of crop straw, cottonseed hulls, and bagasse proportionately. The composting procedure in the medium preparation phase lasts 6 months. Then, the fertile fungi medium is packed into fungi bags. Each fungi bag must be autoclaved and sterilized in a furnace for at least $4 \mathrm{~h}$. Thereafter, the fungi spawns are placed into the cavities for mycelium incubation. This phase lasts for approximately 100-120 days. Finally, the fungi are harvested.

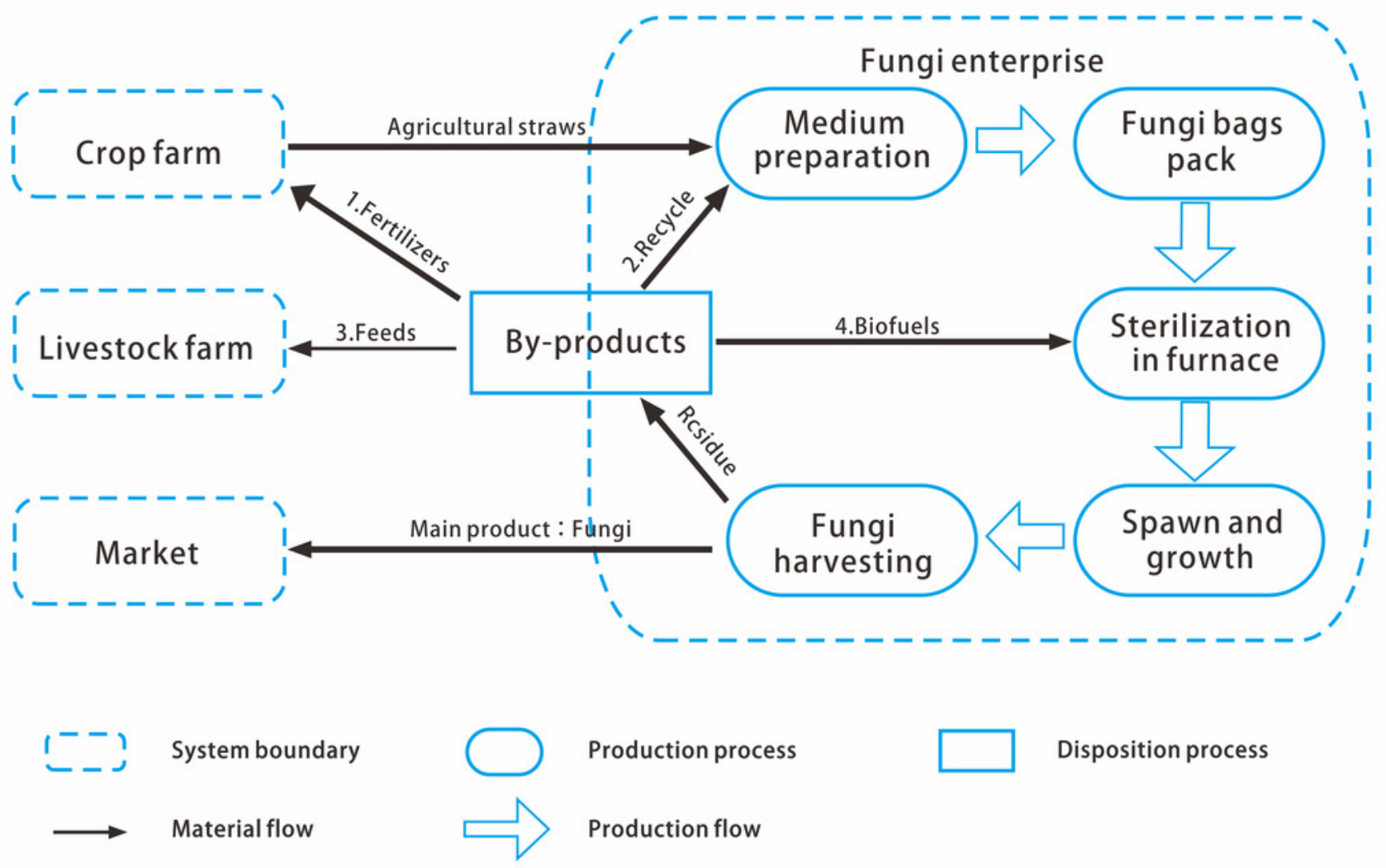




\section{Table $\mathbf{1}$ (on next page)}

The baseline data in the case study

The prices and quantities of output and input which described the production function in the pilot plant. 
Table 1. The baseline data in the case study

\begin{tabular}{|c|c|c|}
\hline & Price & Quantity \\
\hline \multicolumn{3}{|l|}{ Output } \\
\hline Fungi & $12(\mathrm{CHY} / \mathrm{kg})$ & 3882(ton) \\
\hline By-products & $0.1(\mathrm{CHY} / \mathrm{kg})$ & 1519(ton) \\
\hline \multicolumn{3}{|l|}{ Input } \\
\hline Straw & $0.601(\mathrm{CHY} / \mathrm{kg})$ & 1146.23(ton) \\
\hline Seed hull & $1.8(\mathrm{CHY} / \mathrm{kg})$ & 1811.78(ton) \\
\hline Bagasse & $0.3(\mathrm{CHY} / \mathrm{kg})$ & 406.73(ton) \\
\hline Bran & $1.3(\mathrm{CHY} / \mathrm{kg})$ & 184.88(ton) \\
\hline Cornstarch & $2.8(\mathrm{CHY} / \mathrm{kg})$ & 147.9(ton) \\
\hline Spawn(CHY/kg) & $1(\mathrm{CHY} / \mathrm{kg})$ & 1450 (ton) \\
\hline Employment & 55200(CHY/year) & 85 \\
\hline Electricity & $0.57(\mathrm{CHY} / \mathrm{kvh})$ & $4.66 \times 10^{6}(\mathrm{kvh})$ \\
\hline Fresh water & $2.2(\mathrm{CHY} /$ ton $)$ & 2。 $15 \times 10^{4}$ (ton) \\
\hline
\end{tabular}

2 


\section{Table 2 (on next page)}

Simulation results of output and input quantities

The results of fungi production output and input under five simulation scenarios, including four price scenarios (fungi, straw, seed hull and labors' wage) and one scale scenario. Higher market (output) prices and lower input prices can urge the plant to improve its production intensity. Besides, the production behaviors of the pilot plant are more sensitive to scale shrink than to scale expansion; moreover, the pilot plant is in the phase of decreasing returns to scale. 
Table 2. Simulation results of output and input quantities.

\begin{tabular}{|c|c|c|c|c|c|c|c|}
\hline \multirow[b]{2}{*}{ Scenario } & \multicolumn{2}{|c|}{ Output } & \multicolumn{5}{|c|}{ Input } \\
\hline & $\begin{array}{c}\text { Fungi } \\
\text { (ton) }\end{array}$ & $\begin{array}{c}\text { By-pro. } \\
\text { (ton) }\end{array}$ & $\begin{array}{c}\text { Medium } \\
\text { (ton) }\end{array}$ & $\begin{array}{c}\text { Spawn } \\
\text { (ton) }\end{array}$ & Employ. & $\begin{array}{c}\begin{array}{c}\text { Electricity } \\
(\text { kv.h) }\end{array} \\
\end{array}$ & $\begin{array}{c}\text { Water } \\
\text { (ton) }\end{array}$ \\
\hline Base (Optimization) & 3882 & 1519 & 3698 & 1450 & 85 & $4.66 \times 10^{6}$ & $2.35 \times 10^{4}$ \\
\hline \multicolumn{8}{|l|}{ Scenario I: Fungi } \\
\hline Price decrease $10 \%$ & 3652 & 1429 & 3478 & 1364 & 80 & $4.38 \times 10^{6}$ & $2.21 \times 10^{4}$ \\
\hline Price increase $10 \%$ & 4156 & 1626 & 3959 & 1552 & 91 & $4.99 \times 10^{6}$ & $2.51 \times 10^{4}$ \\
\hline \multicolumn{8}{|l|}{ Scenario II: Ag. Straw } \\
\hline Price decrease $10 \%$ & 3914 & 1531 & 3727 & 1462 & 86 & $4.70 \times 10^{6}$ & $2.37 \times 10^{4}$ \\
\hline Price increase $10 \%$ & 3866 & 1513 & 3682 & 1444 & 85 & $4.64 \times 10^{6}$ & $2.34 \times 10^{4}$ \\
\hline \multicolumn{8}{|c|}{ Scenario III: Ct. seed hull } \\
\hline Price decrease $10 \%$ & 4005 & 1567 & 3811 & 1496 & 88 & $4.81 \times 10^{6}$ & $2.42 \times 10^{4}$ \\
\hline Price increase $10 \%$ & 3786 & 1481 & 3575 & 1414 & 83 & $4.54 \times 10^{6}$ & $2.29 \times 10^{4}$ \\
\hline \multicolumn{8}{|l|}{ Scenario: IV Wage } \\
\hline Decline $10 \%$ & 4062 & 1589 & 3869 & 1517 & 89 & $4.87 \times 10^{6}$ & $2.47 \times 10^{4}$ \\
\hline Upraise $10 \%$ & 3739 & 1463 & 3561 & 1397 & 82 & $4.49 \times 10^{6}$ & $2.26 \times 10^{4}$ \\
\hline \multicolumn{8}{|l|}{ Scenario V: Scale } \\
\hline Shrink $10 \%$ & 3402 & 1331 & 3240 & 1271 & 75 & $4.08 \times 10^{6}$ & $2.06 \times 10^{4}$ \\
\hline Expand $10 \%$ & 4158 & 1627 & 3960 & 1553 & 92 & $4.99 \times 10^{6}$ & $2.51 \times 10^{4}$ \\
\hline
\end{tabular}




\section{Table 3 (on next page)}

Simulation results of economic and environmental performances

The plant is motivated to increase input and expand its output to generate high income when the output price increases. Among the three input price scenarios, wage changes can cause the most significant fluctuations in each economic or environmental column. Straw price changes exhibit the least impact on both performances, and the cottonseed hull scenario lies in the middle. 
Table 3. Simulation results of economic and environmental performances.

\begin{tabular}{|c|c|c|c|c|c|}
\hline \multirow[b]{2}{*}{ Scenario } & \multicolumn{3}{|c|}{ Economic (million CHY) } & \multicolumn{2}{|c|}{ Environmental (ton) } \\
\hline & $\begin{array}{c}\text { Total } \\
\text { Benefit }\end{array}$ & $\begin{array}{c}\text { Net } \\
\text { Benefit } \\
\end{array}$ & Cost & $\begin{array}{c}\text { Straw disp. } \\
\text { in plant }\end{array}$ & Straw to field \\
\hline Base & 46.7 & 25.4 & 21.3 & 1146 & 204 \\
\hline \multicolumn{6}{|l|}{ Scenario I: Fungi } \\
\hline Price decrease $10 \%$ & 39.6 & 19.3 & 20.3 & 1078 & 272 \\
\hline Price increase $10 \%$ & 55.0 & 32.6 & 22.4 & 1227 & 123 \\
\hline \multicolumn{6}{|l|}{ Scenario II: Ag. Straw } \\
\hline Price decrease $10 \%$ & 47.1 & 25.7 & 21.4 & 1156 & 195 \\
\hline Price increase $10 \%$ & 46.5 & 25.2 & 21.3 & 1141 & 209 \\
\hline \multicolumn{6}{|l|}{ Scenario III: Ct. seed hull } \\
\hline Price decrease $10 \%$ & 48.2 & 26.7 & 21.5 & 1182 & 168 \\
\hline Price increase $10 \%$ & 45.6 & 24.4 & 21.2 & 1118 & 232 \\
\hline \multicolumn{6}{|l|}{ Scenario IV: Wage } \\
\hline Decline $10 \%$ & 48.9 & 27.3 & 21.6 & 1199 & 151 \\
\hline Upraise 10\% & 45.0 & 23.8 & 21.2 & 1104 & 246 \\
\hline \multicolumn{6}{|l|}{ Scenario VI: Scale } \\
\hline Shrink 10\% & 41.0 & 21.7 & 19.3 & 1004 & 346 \\
\hline Expand $10 \%$ & 50.1 & 27.6 & 22.5 & 1228 & 122 \\
\hline
\end{tabular}




\section{Table 4 (on next page)}

Sensitivity results of economic and environmental performances

Expanding the production scale can be an efficient means of achieving high economic returns and dispose of additional agricultural straws because market prices and average wage levels cannot be controlled by a single plant. 
Table 4. Sensitivity results of economic and environmental performances.

\begin{tabular}{lccccccccccc}
\hline & \multicolumn{2}{c}{ Fungi } & \multicolumn{2}{c}{ Ag. straw } & \multicolumn{2}{c}{ Ct. seed hull } & \multicolumn{2}{c}{ Wage } & \multicolumn{3}{c}{ Scale } \\
& Down & up & Down & up & down & up & down & up & Down & Up \\
\hline Total Benefit & -1.60 & 1.67 & -0.01 & -0.13 & 0.23 & -0.33 & 0.37 & -0.45 & -1.31 & 0.62 \\
Net Benefit & -2.43 & 2.76 & 0.12 & -0.08 & 0.49 & -0.42 & 0.73 & -0.61 & -1.47 & 0.82 \\
Cost & -0.45 & 0.54 & 0.04 & 0.01 & 0.09 & -0.04 & 0.13 & -0.07 & -0.93 & 0.57 \\
Employment & -0.59 & 0.71 & 0.12 & -0.12 & 0.35 & -0.24 & 0.47 & -0.35 & -1.18 & 0.82 \\
Straw Disposal & -0.59 & 0.71 & 0.08 & -0.04 & 0.31 & -0.25 & 0.46 & -0.37 & -1.24 & 0.71 \\
\hline
\end{tabular}

2 